\title{
E-Learning in Gynecologic Oncology for Obstetrics and Gynecology Residents
}

\author{
Amber Murphy ${ }^{1}$, Laurie Elit ${ }^{2 *}$ and Ilana Bayer ${ }^{3}$ \\ ${ }^{1}$ Health Sciences Program, McMaster University, Canada \\ ${ }^{2}$ Department of Obstetrics and Gynecology, McMaster University, Canada \\ ${ }^{3}$ Department of Pathology and Molecular Medicine, McMaster University, Canada
}

Submission: January 29, 2017; Published: February 14, 2017

*Corresponding author: Laurie Elit, Department of Gynecologic Oncology, McMaster University, 699 Concession Street, Hamilton, Ontario, L8V 5C2, Canada, Tel: 905 385688; Email: elitlor@hhsc.ca

Abstract

Objective: To determine the feasibility of creating and implementing an elearning module in a high and low resource setting Obstetrics and Gynecology residency program.

Method: An elearning module focused on Gestational Trophoblastic Disease (GTD) was created. Surveys assessing, readability, resident satisfaction with design and layout and content were conducted.

Outcomes: Thirty out a possible 41 residents in Georgetown, Guyana and Hamilton, Canada provided feedback on the module. (80\% return rate). $79 \%$ of Guyanese and $75 \%$ of Canadian residents felt the GTD elearning module to be effective was effective in enhancing their learning.

Conclusion: e-learning can be used as a supplemental technique to enhance learning in gynecologic oncology residency programs. This has been evaluated in both a low and high resource setting with similar feedback.

Keywords: E-learning; Gestational trophoblastic disease; Readability

\section{Introduction}

Online learning or e-learning is an educational approach that can be utilized to supplement traditional classroom teaching styles [1]. It has been widely accepted across many secondary school districts in an attempt to fill in curricular gaps and enhance student learning [1] but, is yet to be added as a mandatory component of the medical school curriculum. This particular report will discuss the effectiveness of e-learning as a supplemental learning tool for resident OB/GYN students in Southern and Northern America, Georgetown, Guyana and Hamilton, Ontario, respectively. Conclusions will be drawn from a short assessment survey that residents completed after watching an e-learning module on Gestational Trophoblastic Disease (GTD).

\section{Methods}

A needs assessment questionnaire was distributed to 41 residency directors and educators across Canada. The results revealed that there are a limited number of resident educators using e-learning in their OB/GYN programs, but, of the 5 responders who indicated use of e-learning modules, the majority of them found it to be an effective supplementary learning modality (scoring 6-8 out of 10 on a likert scale) [2].

After making this conclusion, an e-learning module on GTD was developed to educate residents on the prevalence of the disease, its complexity and treatment. The module is composed of learning objectives which include: 1) the ability to properly diagnose a patient using patient history, physical examinations, lab-tests, and radiological investigations 2) differentiate between high- and low-risk diseases and 3) describe the different treatment options and their effectiveness. The module also includes a pre-test that is designed to establish the resident's foundational knowledge on the subject; the core content which is presented in an engage/interactive format with each slide building off of the previous one; a case study that is presented halfway through the module and includes multiple choice questions to assess knowledge attainment; and finally, a post-test that is used to determine resident comprehension of the module content. Upon completing the module, 3 gynecologic oncologists provided feedback on its content and structure. Amendments were made and the module was inputted into 
an Articulate software program. At this point, the module was released online to be assessed by residents.

To determine the effectiveness of e-learning as a supplemental learning tool for OB/GYN residents, a survey evaluating the use of e-learning was developed. The survey was composed of 19 questions and was distributed to residents from one OB/GYN program in South America and one in North America. The survey used a variety of question types in order to receive constructive feedback from residents. The survey questions include: multiple choice, list (radio), Array (10 point likert scale), Array (5 point likert scale), yes/no, and long free text questions. These question types were used to assess the GTD module's readability and resident satisfaction with the design and layout of the module and its content. Residents from both jurisdictions were able to watch the module online. Residents from South America were able to view the module through a large TV screen in a classroom setting. Residents from North America used their personal computers to view the module. Participants from South America completed the survey by hand and those from North America accessed the survey via weblink.

In 2012, Dr. Margaret Larkins-Pettigrew and Tia Melton initiated the Women, Neonates, Diversity, Outreach, Opportunities and Research Program (WONDOOR) [3]. This program entails a four-year degree that is designed to educate and train OB/GYN residents in global health [3]. The program is organized so that an attending physician visits Guyana for one week per month to educate residents through the use of a themed module that caters to their desired specialty or interest [3]. Since. Since module directed education has already been implemented in the structure of the WONDOOR OB/GYN education program, additional modules on $\mathrm{OB} / \mathrm{GYN}$ topics that are accessible to the residents at their convince could provide a valuable educational resource.

The $0 B / G Y N$ residency program at McMaster University located in Hamilton, Ontario differs from the OB/GYN program at Georgetown Public Hospital in that it is a five-year residency program [4]. Additionally, resident education is designed to be "problem-centered and experience based [4]." Residents begin the program under heightened faculty supervision [4]. As their skills develop and they evolve as physicians, the level of supervision decreases and they become predominately independent. Where the WONDOOR's OB/GYN program is structured to teach residents didactically, McMasters OB/GYN program is focused on self-directed, hands-on learning. With that being said, nearly all McMaster residents who took part in the survey have been exposed to e-learning and the overall impression is that it has been a useful educational resource to rely on for supplemental information.

\section{Results}

Out of 21 responders, 14 residents from South America completed the survey in full, yielding a return rate of $67 \%$. From the pool of North American residents, 16 out of a possible 20 participants answered all of the survey questions which resulted in a return rate of $80 \%$. In comparing responses from both districts, $43 \%$ of the participants from South America were level-1 residents while the survey participants from North America were distributed evenly between level-2, level-3, level-4, and level-5 of the residency program with $25 \%$ of the survey population representing each level, except level-1. 86\% of the South American participants and $75 \%$ of the North American participants stated that the module took no longer than 60 minutes to complete. This includes the time it took the residents to complete the pre- and post- test multiple choice questions (MCQ) (8 pre-test questions and 10 post-test questions).

$79 \%$ (scores 7-10 out of 10) of South American participants and $75 \%$ (scores $7-9$ out of 10) of the North American participants stated that the GTD e-learning module was effective in enhancing their learning experience.

On a scale from 1 (poor) to 5 (excellent) 71\% of the South American participants stated that the concepts covered in the e-learning module were easy to understand (rated 5 out of 5). $88 \%$ of the North American participants gave the e-learning module a rating of 4 or 5 out of 5 for concept comprehension. Therefore, it is reasonable to assume that the questions assessing the module content were transparent and that the residents were confident in their knowledge of the content and in their ability to solve the presented problems [5]. Across both districts nearly all participants stated that they would prefer that the e-learning module concepts covered in this module be taught through a combination of e-learning and didactic teaching (e.g. module as pre-homework). As mentioned previously, a "blended" teaching style has positive outcomes associated with student learning. Three out of 14 residents from South America stated that they [1] had no experience with e-learning while all residents from North America who responded to the survey had a previous and similar experience with e-learning. Despite the fact that residents from South America are working in low resource settings the majority of them are still able to access online resources such as e-learning modules. Therefore, one can conclude that e-learning modules are an accessible supplemental learning tool for all residents.

In terms of knowledge acquisition, didactic teaching was the most beneficial aspect of the module for South American residents while the case study was the most beneficial aspect for North American residents. Additionally, both the pre- and post-tests were marked valuable by the majority of residents from both districts. Providing residents with a case study and MCQ's gives them the opportunity to apply the knowledge they learned in the content section of the module to 'real world' situations. Furthermore, it allows them to utilize their problem solving skills, which gives the content they learned some context for application in a clinical setting as they have to determine the cause of the proposed problem and devise a solution [6]. 86\% of participants from both districts rated their overall experience with this e-learning module as being satisfactory or excellent. One aspect of the module deemed least beneficial to knowledge 
acquisition by both populations was the use of a narrator for the module content. This claim holds merit in that the instructor dictating the module content spoke at variable volumes throughout the module.

\section{Discussion}

The GTD module was pilot tested in Guyana to take into account the barriers to implementing a supplemental learning tool in an under serviced area. The barriers to implementation include limited access to the internet and language barriers. The results from the pilot test in Guyana were compared to the results from the pilot test in Hamilton, a city with adequate resources, to assess the difference in how the module was received in both populations. Overall, the results were similar in that both resident groups had similar previous experiences with e-learning and were quite satisfied with the delivery of the module, its content, and content assessment method (predominantly MCQ's).

Er, Ramamurthy, and Pook state that cognitive skills can be assessed effectively through the use of high quality MCQ [6]. Not only are MCQ's an effective assessment tool, they are also efficient in that they cover a large amount of content in a short period of time [6]. Therefore, the use of MCQ's within the e-learning module is ideal to ensure that the module can be completed in a timely fashion.

Thrasher, Coleman, and Atkinson compared the effectiveness of face-to-face training to web-based training, and blended training (a combination of face-to-face and web-based training) to determine its effect on declarative and procedural knowledge [7]. They concluded that web-based training was more effective than face-to-face training in acquiring "know that" knowledge and was equal to teacher-led training of "know how" knowledge [7]. Additionally, the blended training was shown to be more effective for both kinds of learning [7]. This supports the notion that e-learning can be used to supplement resident education, effectively. According to Means, Bakia, and Murphy online learning can be especially beneficial to knowledge attainment of challenging content [8]. In the case of GTD, its diagnosis is quite rare with gestational trophoblastic neoplasia developing in 15\% of women who have had a molar pregnancy, choriocarcinoma occurring in 1 in 40,000 pregnancies, and placental site trophoblastic tumor and epithelioid trophoblastic tumor making up only $0.2 \%$ of all cases of GTD [9].

\section{Conclusion}

While there were some technical difficulties with the computation of the module, the overall consensus is that the pilot test was successful. Nearly $100 \%$ of the survey population claimed that they would prefer to use e-learning as a supplemental learning modality in conjunction with traditional teaching styles instead of using e-learning or teacher-led instruction alone. The evaluation of e-learning to augment education is an important area of research and development that holds great potential for future exploration.

\section{References}

1. Murphy A, Elit L, Bayer I (2015) E-Learning Modules for OB/GYN Residents.

2. Palloff RM, Pratt K, Palloff RM (2013) Lessons from the virtual classroom: the realities of online teaching. Jossey-Bass, San Francisco, USA.

3. Pope RJ (2016) University Hospitals MacDonald Women's Hospital: Building women's health bridges in Guyana.

4. McMaster University Department of Obstetrics and Gynecology: Postgraduate. 2016.

5. Ertmer PA (2015 Essential Readings in Problem-based Learning. West Lafayette, Prude University Press, USA.

6. Er HM, Ramamurthy S, Pook PCK (2014) Can learning outcomes in cognitive domain be assessed effectively using multiple choice questions? A study in an undergraduate pharmacy curriculum. IeJSME 8(3): 9-18.

7. Thrasher EH, Coleman PD, Atkinson JK (2006) Web-based versus classroom-based instruction: an empirical comparison of student performance. JIP 1-9.

8. Means B, Bakia M, Murphy R (2014) Learning Online: What Research Tells us About Whether, When, and How. New York, USA.

9. Strohl AE, Lurain JR (2014) Clinical Epidemiology of Gestational Trophoblastic Disease. Current Obstetrics and Gynecology Reports $3(1): 40-43$
Your next submission with Juniper Publishers will reach you the below assets

- Quality Editorial service

- Swift Peer Review

- Reprints availability

- E-prints Service

- Manuscript Podcast for convenient understanding

- Global attainment for your research

- Manuscript accessibility in different formats

( Pdf, E-pub, Full Text, Audio)

- Unceasing customer service

Track the below URL for one-step submission https://juniperpublishers.com/online-submission.php 